\title{
Simple Technique of Initial Speed Identification for Speed-Sensorless Predictive Controlled Induction Motor Drive
}

Research Article

\author{
Dariusz Stando ${ }^{1,2}$, Marian P. Kazmierkowski $i^{1,2, *}$ \\ ${ }^{1}$ Warsaw University of Technology, Koszykowa 75, 00-662 Warsaw, Poland \\ 2 Sieć Badawcza Łukasiewicz - Instytut Elektrotechniki, ul. Mieczysława Pożaryskiego 28, 04-703 Warszawa, Poland
}

Received: October 07, 2020; Accepted: November 20, 2020

\begin{abstract}
This article presents a simple technique of identifying the initial speed that allows for restarting a sensorless induction motor (IM) drive controlled by a model predictive flux control (MPFC). Initial speed identification is required because, according to the research, the applied current-model reference adaptive system (C-MRAS) can restart the IM after failure only if the error of the initial speed set in the estimator is $<25 \%$. The proposed technique is based on short periods of flux generation for the certain initial speed and observation of the estimated torque respond. The direction of the estimated torque determines whether the real speed is higher or lower than the initial one set in the estimator. In two steps, the algorithm identifies the initial speed with an accuracy of $25 \%$. This allows for a quick restart of the IM from any speed, eliminating the disadvantage of the sensorless drive control system with the C-MRAS speed estimator. The experimental results measured on a $50 \mathrm{~kW}$ drive which illustrates the operation and performances of the system are presented.
\end{abstract}

Keywords: induction motor • sensorless control • model predictive control • MRAS estimators • initial speed identification • restarting IM

\section{Introduction}

Sensorless speed control methods allow to eliminate the mechanical motion sensor (tachogenerator, resolver), which improves the reliability and reduces complexity and costs of hardware and maintenance, so they are widely used in industrial and transportation drives (Holtz, 2002, 2005; Orlowska-Kowalska and Dybkowski, 2011; Abu-Rub et al., 2013; Boldea and Nasar, 2017).

In almost all practical applications, the induction motor (IM) should be immediately restarted after turning off the inverter due to over-current or over-voltage errors, without stopping the rotating drive. Of course, it is necessary that the control system should be able to restart smoothly and speed-up the free running IM. If there is a mechanical speed sensor, there is no problem with magnetizing the motor again. However, the problem arises when the actual speed in the sensorless drive is unknown and large inrush current may occur as a result of differences between the frequency of the inverter and the angular frequency of the rotating IM. Therefore, for restarting sensorless IM drive, estimation of both the initial speed and the rotational direction is required. To solve this problem, various methods have been proposed and investigated for IM drives. These methods can be categorized in the following groups: frequency searching methods, electromotive force (EMF) based, DC current injection based, adaptive full order observer (AFO). In the frequency searching methods, the initial value of the stator frequency is adjusted by the frequency controller to find the minimum input power or stator current, and these methods are more suitable for speed open-loop V/Hz control (Pan et al., 1997; Lee et al., 2017). The EMF-based methods deteriorate in the low-speed range because of the low value of EMF and the effects of stator resistance variations (Tajima et al., 1996; Kondo, 2015; Kobayashi et al., 2016). The DC current injection methods use proportional integral (PI) current 
controllers and are convenient for vector control systems but not for direct torque or predictive torque control (lura et al., 2011; Kikuchi et al., 2018; Yin et al., 2020). The group of AFO-based method is promising and can be used with a combination of predictive torque and flux control; however, it requires a complicated design (Wang et al., 2015; Yang et al., 2017).

In this paper, a simple technique of initial speed identification based on model reference adaptive system (MRAS) sensorless control with predictive torque and flux control system is presented. The proposed technique uses MRAS estimator, generates a sequence of short flux reference pulses and observes the estimated torque response to infer the direction and level of the rotor speed. The experimental results measured on the $50 \mathrm{~kW} I M$ drive illustrate the operation of the developed method.

\subsection{Block scheme of speed-sensorless predictive stator flux and torque control}

The considered speed-sensorless stator model predictive flux control (MPFC) system is presented in Figure 1. Among several approaches to finite control set model predictive control FCS-MPC of three-level inverter-fed drives (Habibullah et al., 2017; Donoso et al., 2018; Zhang et al., 2019), in this work the class of optimal switching sequence (OSS) has been chosen (Vazquez et al., 2017) because it guarantees constant switching frequency of the power inverter. Another important selection was the MPFC scheme because it allows to design the IM predictive model and minimization of the cost function without necessity for labour-intensive weights values selection procedure using the "trial and error" method. This is because the IM torque is expressed in terms of stator flux (Zhang and Yang, 2016).

The detailed design and description of the developed and constructed OSS-MPFC drives are described in Stando (2018) and Stando and Kazmierkowski (2020).

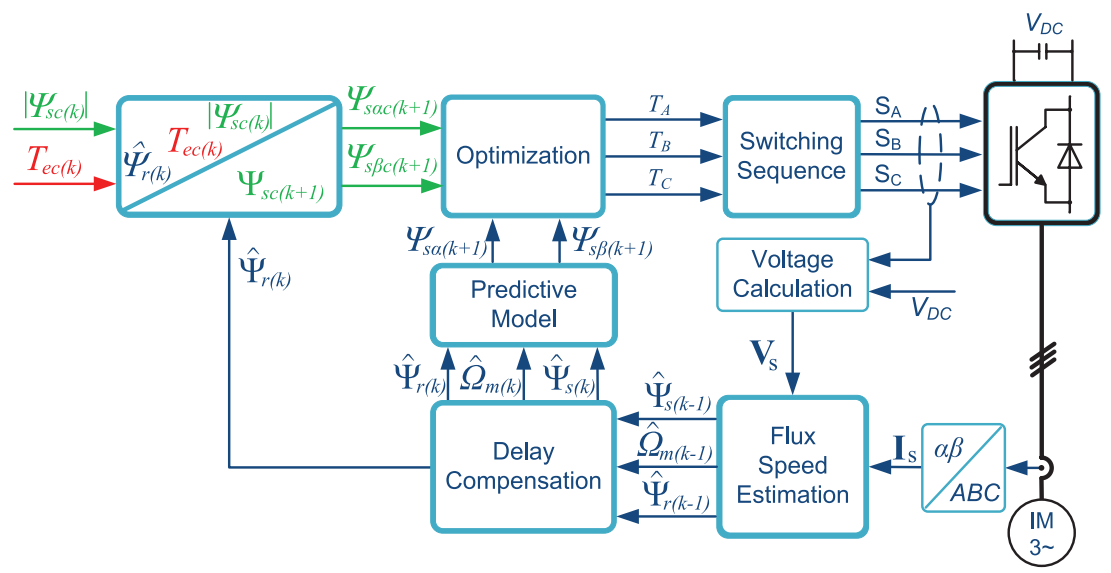

Fig. 1. Block diagram of the optimal switching sequence-model predictive stator flux controlled (OSS-MPFC) IM drive

\section{Speed Estimation with C-MRAS}

In this study, for IM stator flux and speed estimation, the compensated current-model reference adaptive system (C-MRAS) version is used (Figure 2; Orlowska-Kowalska and Dybkowski, 2010). It employs the real IM as the reference model and the full voltage-speed $\left(\mathrm{V}-\Omega_{\mathrm{m}}\right)$ model of the IM (Depenbrock, 1988; Kazmierkowski and Tunia, 1994) as the adaptive model. The C-MRAS, like other variants of MRAS estimators, is parameter dependent; however, it is more robust thanks to real-time correction with measured stator currents (Wang et al., 2014).

The adaptive $\left(\mathrm{V}-\Omega_{m}\right)$ model (Figure 3$)$ is described by the following equations:

$$
\begin{aligned}
& \frac{d \hat{\Psi}_{s \alpha}}{d t}=V_{s \alpha}-R_{s} \hat{I}_{s \alpha} \\
& \frac{d \hat{\Psi}_{s \beta}}{d t}=V_{s \beta}-R_{s} \hat{I}_{s \beta}
\end{aligned}
$$




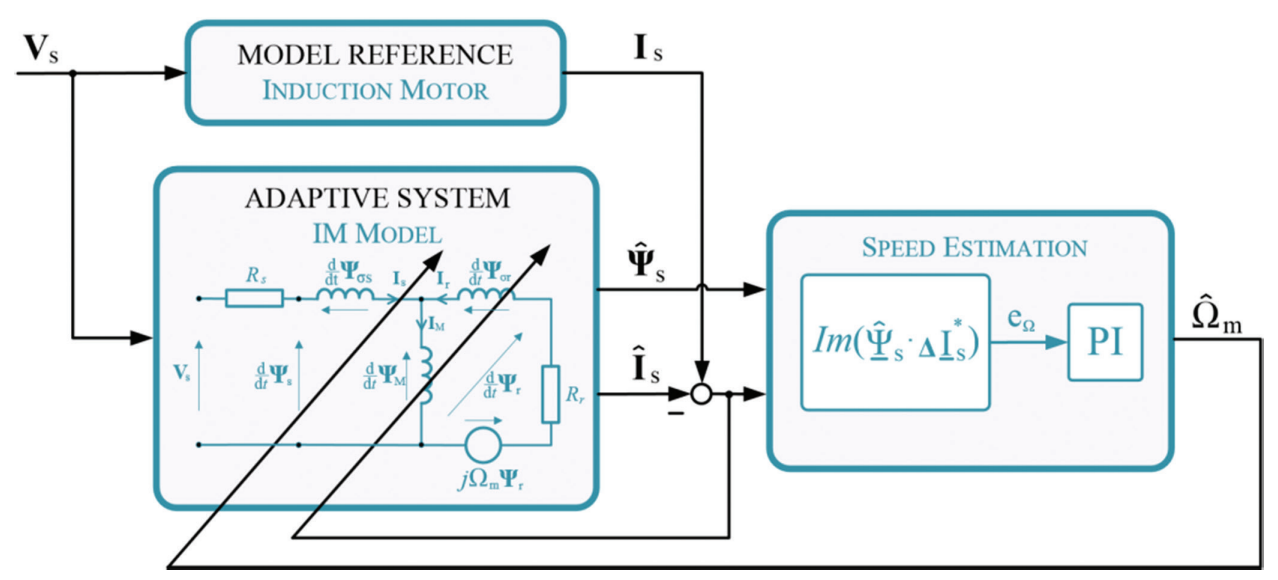

Fig. 2. Block diagram of speed estimation using compensated C-MRAS

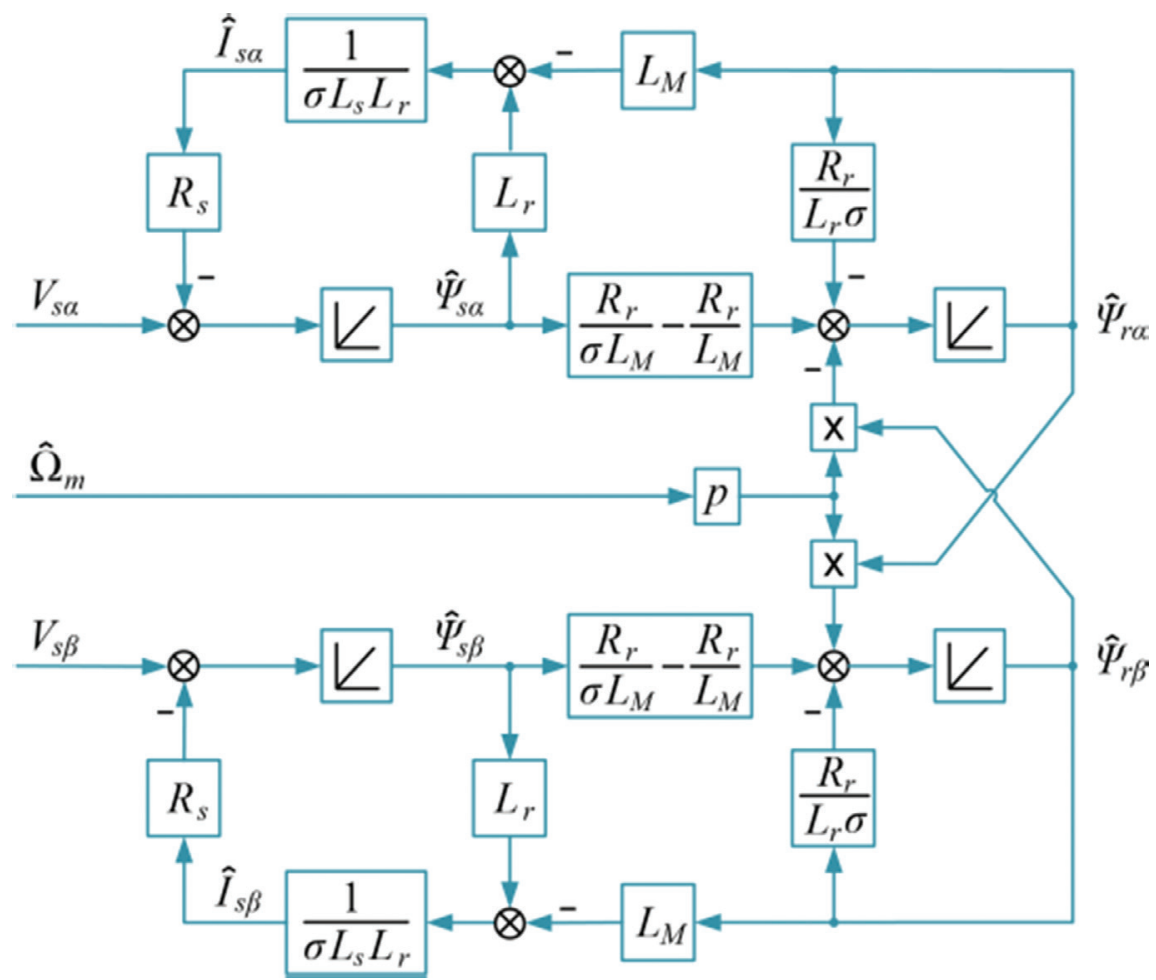

Fig. 3. Voltage-speed flux IM model used as an adaptive system in C-MRAS

$$
\begin{aligned}
& \frac{d \hat{\Psi}_{r \alpha}}{d t}=\frac{R_{r}}{L_{M}}\left(\frac{1}{\sigma}-1\right) \hat{\Psi}_{s \alpha}-\frac{1}{\sigma L_{r}} \hat{\Psi}_{r \alpha}-p_{b} \hat{\Omega}_{m} \hat{\Psi}_{r \beta} \\
& \frac{d \hat{\Psi}_{r \beta}}{d t}=\frac{R_{r}}{L_{M}}\left(\frac{1}{\sigma}-1\right) \hat{\Psi}_{s \beta}-\frac{1}{\sigma L_{r}} \hat{\Psi}_{r \beta}-p_{b} \hat{\Omega}_{m} \hat{\Psi}_{r \alpha} \\
& \hat{I}_{s \alpha}=\frac{L_{r} \hat{\Psi}_{s \alpha}-L_{M} \hat{\Psi}_{r \alpha}}{\sigma L_{s} L_{r}}
\end{aligned}
$$




$$
\hat{I}_{s \beta}=\frac{L_{r} \hat{\Psi}_{s \beta}-L_{M} \hat{\Psi}_{r \beta}}{\sigma L_{s} L_{r}}
$$

where $V_{s}=\left(V_{s \alpha} \cdot V_{s \beta}\right), I_{s}=\left(I_{s \alpha} \cdot I_{s \beta}\right)$ and $\psi_{s}=\left(\psi_{s \alpha} \cdot \psi_{s \beta}\right)$ are the stator voltage vector, the stator current vector and stator flux vector, respectively; $I_{r}=\left(I_{r \alpha \beta}\right)$ and $\psi_{r}=\left(\psi_{r \alpha \beta}\right)$ are the rotor current vector and rotor flux vector, respectively; $\Omega_{m}$ denotes the rotor electrical angular speed; $R_{s}, R_{r}, L_{s}, L_{r}$ and $L_{M}$ are the stator resistance, rotor resistance, stator inductance, rotor inductance and main inductance, respectively; and finally, $p_{b}$ denotes the pair of poles, $J$ is the moment of inertia, $\psi_{s}^{*}$ is conjugate stator flux vector, $T_{L}$ is the load torque, $\sigma$ is the total leakage factor and symbol. denotes the estimated values.

Both models are supplied by the same reference voltage $V_{s}$ (Figure 2). The adaptive system is additionally tuned by two closed loops. The first one considers error between measured current $I_{s}$ and calculated form (3), while the second one the adaptively estimated speed (5). The first closed loop is responsible for offsets compensation introduced mainly from current sensors. The mechanism of offset compensation is realized by two PI controllers, one for each of the $\alpha$ and $\beta$ components. Inputs of these controllers are the current errors $\left(I_{s}-\hat{I}_{s}\right)$ while the outputs are the offset compensation signals added to the right-hand side of Eq. (1). For proper compensation in the whole range of the IM rotor speed, the controller time constant is tuned proportionally to the speed value. Furthermore, the controllers operate very slowly for two reasons: to ensure lack of influence for the estimation in transients because they integrate errors from sinusoidal signals. The second closed loop delivers the mechanical speed $\hat{\Omega}_{m}$ which is estimated based on the error between measured $I_{s}$ and estimated $\hat{\mathrm{I}}_{s}$ currents multiplied by the estimated stator flux vector $\Psi_{s}$ according to (4):

$$
\begin{aligned}
& e_{\Omega}=\operatorname{Im}\left(\hat{\Psi}_{s} \Delta \hat{\mathbf{I}}_{s}\right)=\hat{\Psi}_{s \beta}\left(I_{s \alpha}-\hat{I}_{s \alpha}\right)-\hat{\Psi}_{s \alpha}\left(I_{s \beta}-\hat{I}_{s \beta}\right) \\
& \hat{\Omega}_{m}=K_{p} e_{\Omega}+\frac{K_{p}}{T_{I}} \int e_{\Omega} d t
\end{aligned}
$$

Speed estimation is performed by the PI regulator (5). It is a fundamental method used for this purpose in MRAS, which ensures intuitive tuning of only two parameters (Schauder, 1992; Korzonek and Orlowska-Kowalska, 2016). In the literature, other mechanisms of speed adaptation can be also found, for example, ANN (Gadoue et al., 2009; Maiti et al., 2012) or fuzzy logic (Dybkowski and Orlowska-Kowalska, 2008; Zhang et al., 2019). In this work, parameters of the PI controller, calculated according to the optimum symmetry criterion, were set as $K_{p}=0.31$ and $T_{i}=1.5 \mathrm{~ms}$ (Stando, 2018).

\section{Initial Speed Identification}

In almost all applications, the IM should be immediately restarted after turning off the inverter due to overcurrent or over-voltage errors. If there is a speed sensor, there is no problem with magnetizing the motor again. However, the problem arises when the actual speed is unknown. The simplest solution would be to restart the system with the last known speed, but the difference between the real one and this kept in a memory can be significant. If the difference is too high, the proposed adaptation mechanism will fail. To overcome this issue, the new solution of initial speed identification for MRAS is proposed. As it was investigated, the difference between the real and initial speeds can be even $25 \% \Omega_{N}$. In this range of error, the adaptation mechanism will eliminate the speed estimation error before over-current appears during the magnetizing process. Thanks to this, a quite simple solution can be applied, which is based on detection of the estimated torque sign. The proposed algorithm is shown in Figure 4.

The algorithm is performed in two steps. During each step, a short pulse of flux reference is generated. For this, the IM control method is used. It starts the process of flux generation for a short time, but long enough to notice a change in the motor torque period. When the initial speed is incorrect, the torque impulse appears. The direction of the impulse determines whether the set speed is higher or lower than the actual one. This procedure 
does not cause undesirable behaviour of the drive. The first step is to determine the direction of shaft rotation. For this purpose, the initial speed $\Omega_{m 0}^{*}$ commanded to the estimator is set to zero. In the second step, the initial speed is set to half the nominal one with the sign corresponding to the estimated sign of torque. The second torque impulse gives information about whether the real speed is below or above half the nominal one. After the test, the initial speed for start-up is set as $\pm 25 \% \Omega_{m N}$ or $\pm 75 \% \Omega_{m N}$. The time diagram of the speed division during initial speed identification is shown in Figure 5, and the dependence of the torque sign from set speed and real one is summarized in Table 1.

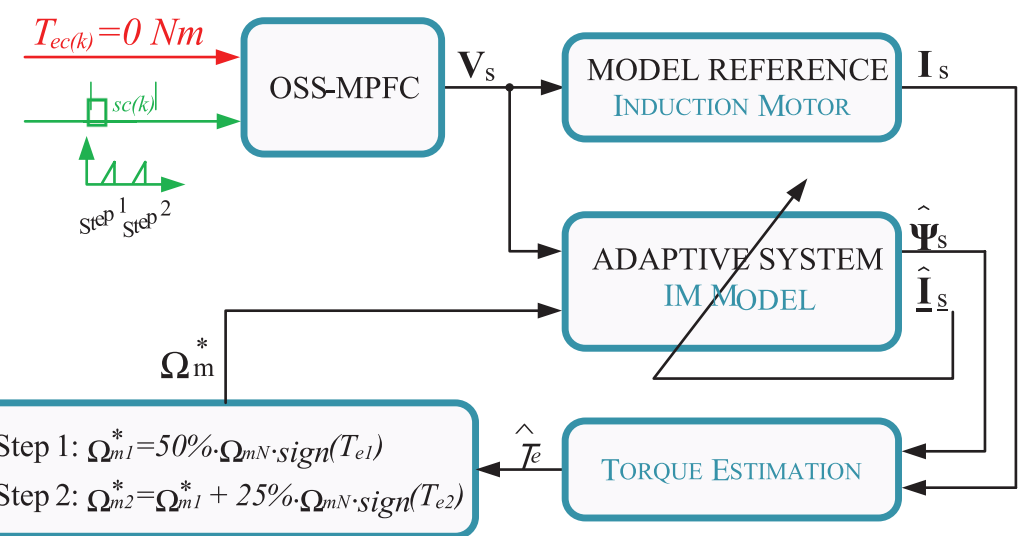

Fig. 4. Block diagram of the initial speed identification algorithm

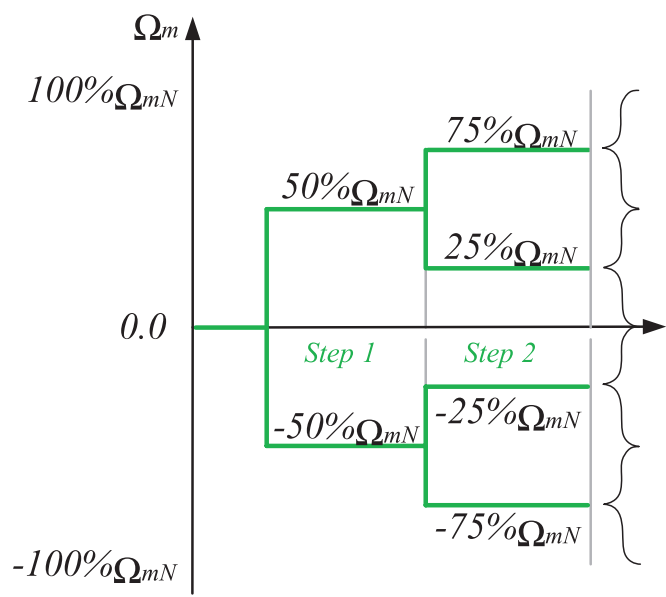

Fig. 5. Time diagram of the speed division during initial speed identification

Table 1. Dependence of the torque sign from estimated $\hat{\Omega}_{m}$ (set $\Omega_{m 0}^{\star}$ ) speed and the real one $\Omega_{m}$

\begin{tabular}{lc}
\hline Step 1 & Step 2 \\
\hline \hline$\Omega_{m 0}^{\star} \hat{T}_{e} \Omega_{m 0}^{\star}$ vs. $\Omega_{m 1}^{\star} \Omega_{m 1}^{\star}$ & $\hat{T}_{e} \Omega_{m 1}^{\star}$ vs. $\Omega_{m 2}^{\star} \Omega_{m 2}^{\star}$ \\
$0.0\left(+>-50 \% \Omega_{m N}\right.$ & $+<-75 \% \Omega_{m N}$ \\
& $->-25 \% \Omega_{m N}$ \\
$0.0-<+50 \% \Omega_{m N}$ & $+<+75 \% \Omega_{m N}$ \\
\hline
\end{tabular}




\section{Experimental Results}

The selected experimental results for the identification of the initial speed are presented in Figures 6-8. In Figure 6, the step-by-step identification process of the initial speed is shown. Before the first step, the speed commanded to MRAS estimator $\Omega_{\text {MRAS }}$ is set to $0 \mathrm{rpm}$. After the first stator flux impulse $\left(t_{1}-t_{2}\right)$, the direction of the rotation is determined from the torque sign. Then, before the second stage, the estimator speed $\Omega_{\text {MRAS }}$ is set to $-50 \% \Omega_{m N}$.

The second stage starts after $250 \mathrm{~ms}$ (this period $\left(t_{2}-t_{3}\right)$ is selected to ensure the accuracy of the estimation over the entire speed range) and determines the speed range of the motor shaft rotation between $0 \% \Omega_{m N}$ and $-25 \% \Omega_{m N}$. When the identification is completed, in time $t_{5}$ begins the start-up of the motor. After $80 \mathrm{~ms}$, the speed estimator identifies the initial speed, which is $-150 \mathrm{rpm}$.

A similar starting process can be observed in the other two figures, where the starting speed was identified, respectively: $-1,700$ rpm in Figure 7 and 700 rpm in Figure 8.

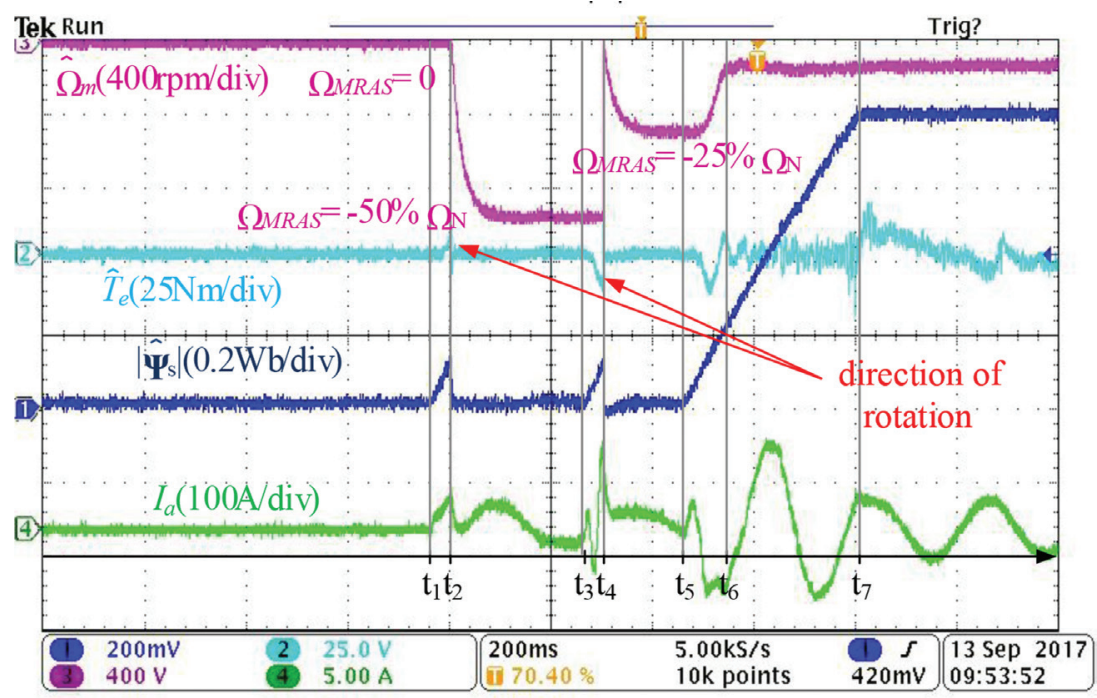

Fig. 6. Start-up with $-150 \mathrm{rpm}$, after initial speed identification, where $\left|\hat{\Psi}_{s}\right|$ is the estimated stator flux, $\hat{T}_{\mathrm{e}}$ is the estimated torque, $\hat{\Omega}_{m}$ is the estimated mechanical speed and $l_{a}$ is the phase current

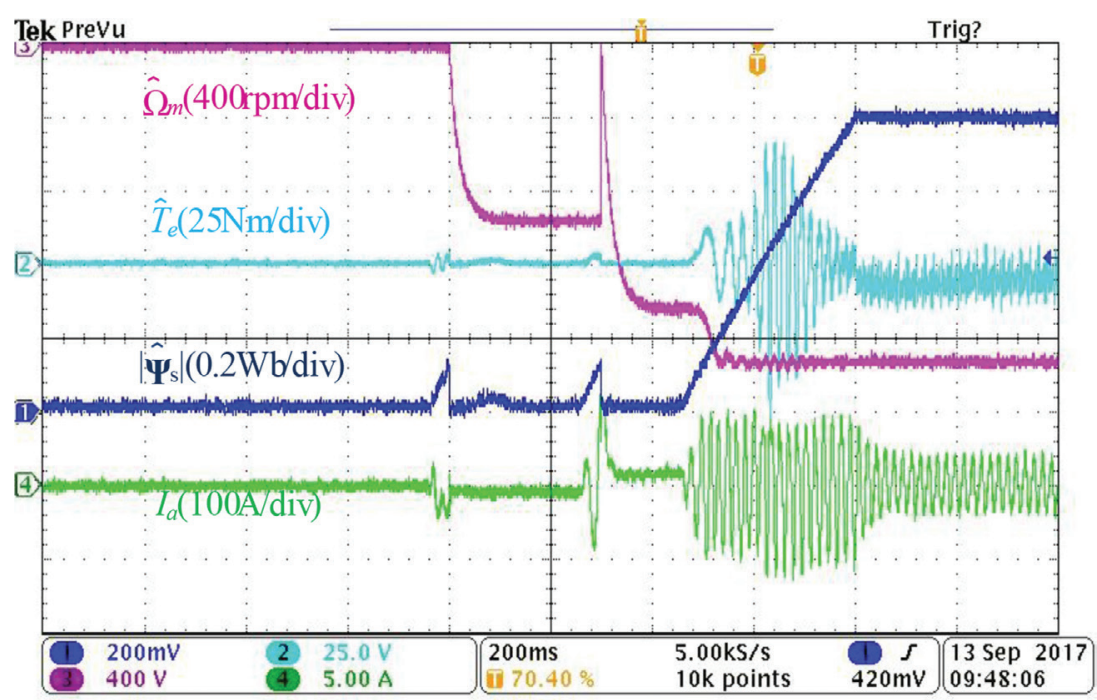

Fig. 7. Start-up with $-1,700 \mathrm{rpm}$, after initial speed identification, where $\left|\hat{\Psi}_{s}\right|$ is the estimated stator flux, $\hat{T}_{\mathrm{e}}$ is the estimated torque, $\hat{\Omega}_{m}$ is the estimated mechanical speed and $l_{a}$ is the phase current 


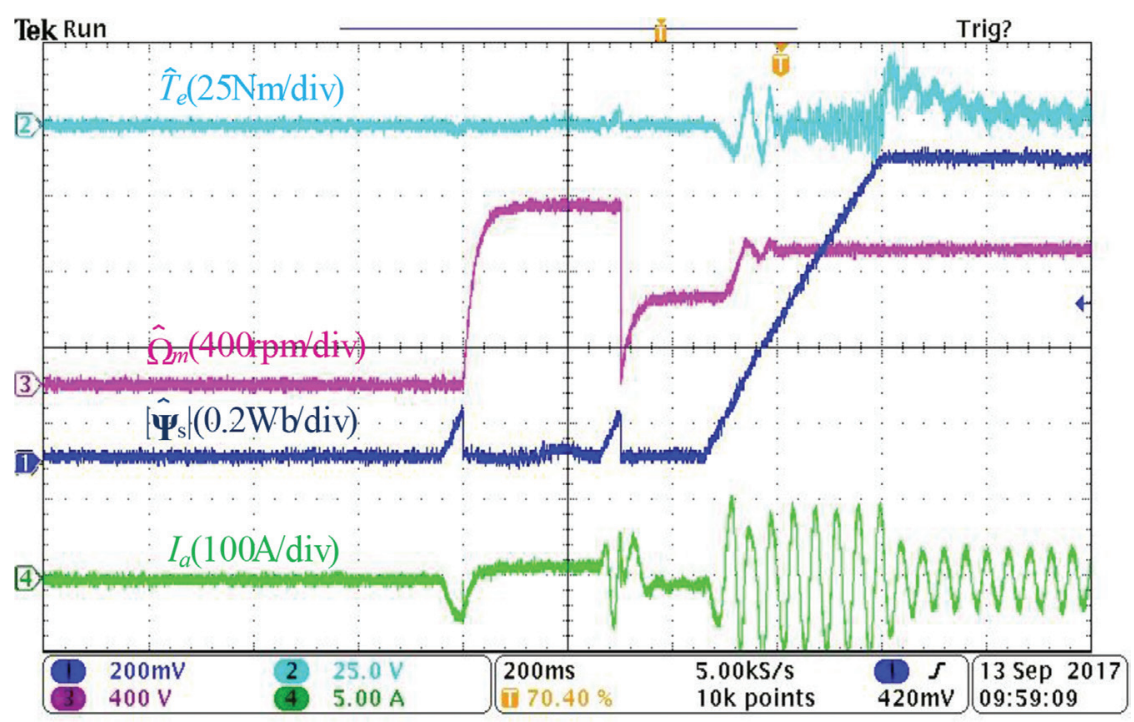

Fig. 8. Start-up with $700 \mathrm{rpm}$, after initial speed identification, where $\left|\hat{\Psi}_{s}\right|$ is the estimated stator flux, $\hat{T}_{e}$ is the estimated torque, $\hat{\Omega}_{m}$ is the estimated mechanical speed and $l_{a}$ is the phase current

\section{Conclusions}

A novel technique of initial speed identification in sensorless IM drive with predictive flux and torque control and C-MRAS estimator has been presented in this paper. The proposed solution is characterised by the following features:

- It is implemented in the drive C-MRAS estimator of torque and stator flux;

- It generates the stator flux pulse reference and observes the sign of the estimated torque;

- The procedure is simple and is performed in two steps. So, the executing time is $<0.5 \mathrm{~s}$;

- It is verified by experimental tests.

\section{References}

Abu-Rub, H., Stando, D. and Kazmierkowski, M. P. (2013). Simple Speed Sensorless DTC-SVM Scheme for Induction Motor Drives. Bulletin of the Polish Academy of Sciences: Technical Sciences, 61(2), pp. 301-307. doi: 10.2478/ bpasts-2013-0028.

Boldea, I. and Nasar, S. A. (2017). Vector Control of AC Drives, Vector Control of AC Drives. doi: 10.1201/9780203734407.

Depenbrock, M. (1988). Direct Self-Control (DSC) of Inverter-Fed Induction Machine. IEEE Transactions on Power Electronics, 3(4), pp. 420-429. doi: 10.1109/63.17963.

Donoso, F., Mora, A., Cárdenas Dobson, J., Angulo, A., Sáez Hueichapán, D. and Rivera, M. (2018). Finite-Set Model-Predictive Control Strategies for a 3L-NPC Inverter Operating with Fixed Switching
Frequency. IEEE Transactions on Industrial Electronics, 65(5). doi: 10.1109/TIE.2017.2760840.

Dybkowski, M. and Orlowska-Kowalska, T. (2008). Low-Speed Performance of the Stator CurrentBased MRAS Estimator with FL Controller in the Sensorless Induction Motor Drive. In: 11th International Conference on Optimization of Electrical and Electronic Equipment, OPTIM 2008, pp. 75-80. doi: 10.1109/OPTIM.2008.4602460.

Gadoue, S. M., Giaouris, D. and Finch, J. W. (2009). Sensorless Control of Induction Motor Drives at Very Low and Zero Speeds Using Neural Network Flux Observers. IEEE Transactions on Industrial Electronics, 56(8), pp. 3029-3039. doi: 10.1109/ TIE.2009.2024665.

Habibullah, M., Lu, D. D.-C., Xiao, D. and Rahman, M. F. (2017). Finite-State Predictive Torque 
Control of Induction Motor Supplied from a Three-Level NPC Voltage Source Inverter. IEEE Transactions on Power Electronics. doi: 10.1109/ TPEL.2016.2522977.

Holtz, J. (2002). Sensorless Control of Induction Motors. Proceedings of the IEEE, 90(8), pp. 1358-1394.

Holtz, J. (2005). Developments in sensorless AC drive technology. In: Proceedings of the International Conference on Power Electronics and Drive Systems, pp. 9-16. doi: 10.1109/ peds.2005.1619652.

Iura, H., Ide, K., Hanamoto, T. and Chen, Z. (2011). An Estimation Method Of Rotational Direction and Speed for Free-Running AC Machines without Speed and Voltage Sensor. IEEE Transactions on Industry Applications, 47(1), pp. 153-160. doi: 10.1109/TIA.2010.2091670.

Kazmierkowski, M. P. and Tunia, H. (1994). Automatic Control of Converter-Fed Drives. Amsterdam-London-New York-Tokyo, Warsaw: Elsevier Ltd.

Kikuchi, T., Matsumoto, Y. and Chiba, A. (2018). Fast Initial Speed Estimation for Induction Motors in the Low-Speed Range. IEEE Transactions on Industry Applications, 54(4), pp. 3415-3425. doi: 10.1109/ TIA.2018.282.5292.

Kobayashi, N., Kondo, K. and Yamazaki, O. (2016). Induction Motor Speed-Sensorless Vector Control Using Mechanical Simulator and Disturbance Torque Compensation. IEEE Transactions on Industry Applications, 52(3), pp. 2323-12331. doi: 10.1109/TIA.2016.2524440.

Kondo, K. (2015). Re-Starting Technologies for Rotational Sensorless Controlled AC Motors at the Rotating Status. In: Proceedings of 10th Asian Control Conference, pp. 1-6. doi: 10.1109/ ASCC.2015.7244839.

Korzonek, M. and Orlowska-Kowalska, T. (2016). Stability Analysis of MRASSCC Speed Estimator in Motoring and Regenerating Mode. Power Electronics and Drives, 1(2), pp. 113-131.

Lee, K., Ahmed, S. and Lukic, S. M. (2017). Universal Restart Strategy for Scalar V/f Controlled Induction Machines. IEEE Transactions on Industry Applications, 53(6), pp. 5489-5495. doi: 10.1109/ TIA.2017.2733497.

Maiti, S., Verma, V., Chakraborty, C. and Hori, Y. (2012). An Adaptive Speed Sensorless Induction Motor Drive with Artificial Neural Network for Stability Enhancement. IEEE Transactions on Industrial Informatics, 8(4), pp. 757-766. doi: 10.1109/ TII.2012.2210229.
Orlowska-Kowalska, T. and Dybkowski, M. (2010). Stator-current-based MRAS Estimator for A Wide Range Speed-Sensorless Induction-Motor Drive. IEEE Transactions on Industrial Electronics, 57(4), pp. 1296-1308. doi: 10.1109/TIE.2009. 2031134.

Orlowska-Kowalska, T. and Dybkowski, M. (2011). Performance Analysis of the Sensorless Induction Motor Drive System Under Faulted Conditions. In: 2011 IEEE EUROCON - International Conference on Computer as a Tool. IEEE, pp. 1-4. doi: 10.1109/ EUROCON.2011.5929414.

Pan, H., Springob, L. and Holtz, J. (1997). Improving the Start and Restart Behavior Trough State Recognition of AC Drives. In: Proceedings of Power Conversion Conference Nagaoka, pp. 589594. doi: 10.1109/pccon.1997.638246.

Schauder, C. (1992). Adaptive Speed Identification for Vector Control of Induction Motors without Rotational Transducers. IEEE Transactions on Industry Applications, 28(5), pp. 1054-1061. doi: 10.1109/28.158829.

Stando, D. (2018). Predictive Control of 3-Level InverterFed Sensorless Induction Motor Drive. PhD Thesis. Warsaw: Warsaw University of Technology, Faculty of Electrical Engineering.

Stando, D. and Kazmierkowski, M. P. (2020). Constant Switching Frequency Predictive Control Scheme for Three-Level Inverter-Fed Sensorless Induction Motor Drive. Bulletin of the Polish Academy of Sciences Technical Sciences, 68(5). doi: 10.24425/ bpasts.2020.134668.

Tajima, H., Matsumoto, Y. and Umida, H. (1996). Speed Sensorless Vector Control Method for an Industrial Drive System. IEEJ Transactions on Industry Applications, 116(11), pp. 1103-1109. doi: 10.1541/ ieejias.116.1103.

Vazquez, S., Rodriguez, J., Rivera, M., Franquelo, L. G. and Norambuena, M. (2017). Model Predictive Control for Power Converters and Drives: Advances and Trends. IEEE Transactions on Industrial Electronics, 64(2). doi: 10.1109/ TIE.2016.2625238.

Wang, F., Chen, Z., Stolze, P., Stumper, J.-F., Rodríguez, J. and Kennel, R. (2014). Encoderless Finite-State Predictive Torque Control for Induction Machine with a Compensated MRAS. IEEE Transactions on Industrial Informatics. IEEE Computer Society, 10(2), pp. 1097-1105. doi: 10.1109/ TII.2013.2287395.

Wang, H., Sun, W., Yu, Y., Wang, G. and Xu, D. (2015). Robustness improvement for adaptive 
full order observer in sensorless induction motor drives. In: 9th International Conference on Power Electronics - ECCE Asia: 'Green World with Power Electronics', ICPE 2015-ECCE Asia. doi: 10.1109/ ICPE.2015.7167961.

Yang, H., Zhang, Y., Walker, P. D., Zhang, N. and Xia, B. (2017). A Method to Start Rotating Induction Motor Based on Speed Sensorless Model-Predictive Control. IEEE Transactions on Energy Conversion. IEEE, 32(1), pp. 359-368. doi: 10.1109/ TEC.2016.2614670.

Yin, S., Xia, J., Zhao, Z., Zhao, L., Liu, W., Diao, L. and Jatskevich, J. (2020). Fast Restarting of Free-Running Induction Motors Under Speed-
Sensorless Vector Control. IEEE Transactions on Industrial Electronics, 67(7), pp. 6124-6134. doi: 10.1109/TIE.2019.2934077.

Zhang, Y. and Yang, H. (2016). Two-Vector-Based Model Predictive Torque Control Without Weighting Factors for Induction Motor Drives. IEEE Transactions on Power Electronics, 31(2), pp. 1381-1390. doi: 10.1109/TPEL.2015.2416207.

Zhang, Y., Bai, Y., Yang, H. and Zhang, B. (2019). Low Switching Frequency Model Predictive Control of Three-Level Inverter-Fed IM Drives with SpeedSensorless and Field-Weakening Operations. IEEE Transactions on Industrial Electronics, 66(6), pp. 4262-4272. doi: 10.1109/TIE.2018.2868014. 
Initial speed identification for speed-sensorless predictive controlled IM drive

Appendix A

A.1. Motor and Inverter data

Table A1. Parameters of 3L-NPC inverter

\begin{tabular}{lc}
\hline Parameter & Value \\
\hline \hline$S_{N}$ & $200 \mathrm{kV} \mathrm{A}$ \\
$I_{N}$ & $300 \mathrm{~A}$ \\
$V_{N}$ & $3 \times 400 \mathrm{~V}$ \\
\hline
\end{tabular}

Table A2. Parameters of IM (STDA 200L4)

\begin{tabular}{lc}
\hline Parameter & Value \\
\hline \hline$P_{N}$ & $50 \mathrm{~kW}$ \\
$I_{N}$ & $88 \mathrm{~A}$ \\
$V_{N}$ & $380 \mathrm{~V}$ \\
$f_{N}$ & $65 \mathrm{~Hz}$ \\
$P_{b}$ & 2 \\
$\Omega_{m N}$ & $1,917 \mathrm{rpm}$ \\
$T_{\text {eN }}$ & $250 \mathrm{Nm}$ \\
$R_{S}$ & $0.067 \Omega$ \\
$R_{r}$ & $0.046 \Omega$ \\
$L_{S}$ & $0.02346 \mathrm{H}$ \\
$L_{r}$ & $0.02346 \mathrm{H}$ \\
$L_{M}$ & $0.023 \mathrm{H}$ \\
\hline
\end{tabular}

198 